\title{
What's Gender Got to Do with It? Incivility in the Federal Courts
}

\author{
Lilia M. Cortina, Kimberly A. Lonsway, Vicki J. Magley, Leslie V. \\ Freeman, Linda L. Collinsworth, Mary Hunter, \\ and Louise F. Fitzgerald
}

The current study examines experiences of interpersonal mistreatment in federal litigation among a random sample of 4,608 practicing attomeys. Using both quantitative and qualitative survey data, we documented the nature and interplay of general incivility, gender-related incivility, and unwanted sexual attention. Nearly $75 \%$ of female attorneys had experienced some form of this misconduct in the previous five years, compared to half of male attorneys. An in-depth examination of instigators revealed that not only fellow attorneys but also federal judges, court personnel, marshals, and court security officers instigated the inappropriate behavior. We further found that most attomeys responded to this mistreatment with avoidance and denial; few used or trusted existing reporting mechanisms. The current study surpassed simple prevalence estimates to document effects of interpersonal mistreatment on the professional well-being of targeted attorneys. We discuss implications of these results, drawing on theories of social dominance, sexrole spillover, cognitive stress, organizations, and intervention.

Lilia M. Cortina is assistant professor in the Departments of Psychology and Women's Studies, University of Michigan, Ann Arbor; Kimberly A. Lonsway is research director at the National Center for Women and Policing, Feminist Majority Foundation; Vicki J. Magley is assistant professor in the Department of Psychology, University of Connecticut; Leslie V. Freeman is managing attorney at Legal Services of Eastern Missouri, St. Louis; Linda L. Collinsworth is a doctoral candidate in counseling psychology, University of Illinois at Urbana-Champaign; Mary Hunter is a research assistant at the Chicago Police Department; and Louise F. Fitzgerald is professor in the Departments of Psychology and Women's Studies at the University of Illinois at Urbana-Champaign.

The Eighth Circuit Gender Fairness Task Force supported this research. We are grateful to the following individuals for their invaluable assistance with the project: Jill Hunter Williams, Regina Day Langhout, and Amanda J. Hammond.

Please address correspondence to Lilia M. Cortina, University of Michigan, Department of Psychology, 525 E. University, Ann Arbor, MI 48109-1109. E-mail: lilia@umich.edu. 


\section{INTRODUCTION: BACKGROUND}

Addressing the opening session of the 1971 American Law Institute, Chief Justice Warren Burger warned of rising levels of incivility in the practice of law:

Lawyers, judges, and law professors must see that an undisciplined and unregulated profession will destroy itself, will fail in its mission, and will not restore public confidence in the profession. $(1971,217)$

Two decades later, Justice Sandra Day O'Connor introduced the final report of the Ninth Circuit Gender Bias Task Force by summarizing evidence of gender bias in the federal court system, arguing that "when people perceive gender bias in a legal system, whether they suffer from it or not, they lose respect for that system, as well as for the law" $(1994,760)$. These quotes highlight two prominent contemporary concerns within the sociolegal community, both of which have fueled heated debate, ambitious self-studies, and calls for action. The first concern stems from a perceived deterioration in civility and professionalism, whereas the second focuses on gender-based misconduct and its derailing effects on the administration of justice. Despite apparent overlap in the spirit and objectives of these two movements, they have evolved in relative isolation from one another. The current paper aims to bridge this divide and integrate the two concerns with empirical data from one federal judicial circuit - providing the most comprehensive evidence to date of attorneys' experiences of general incivility, gendered incivility, and sexual harassment in federal litigation.

\section{Problems of Incivility}

Commentators depict today's attorneys as "modern day gladiators" (Corr and Madden 1995, 9), "professional combatants," and "barbarians of the bar" (Pierce 1995, 60). Civil litigation, they argue, has become an oxymoron (Honeywell 1994; Wallis-Honchar 1997), with attorneys strategically employing such tactics as unreasonable scheduling (Guccione 1997); refusal to comply with discovery requests (Ring 1992); use of depositions as forums for harassment; and intimidation and disparagement of witnesses, opposing parties, and counsel (Corr and Madden 1995). Attorneys report that they encounter uncivil behavior not only from each other but also from members of the bench, whom they describe as often arrogant, impatient, impolite, and too preoccupied with case management to be civil (Hansen 1991; Ring 1992).

Although no empirical evidence substantiates an actual decline in civility among legal professionals, discourse in both the sociolegal and public 
arenas assumes this trend. Critics suggest a number of explanations for this perceived deterioration, including increases in the financial stakes of litigation, lower client loyalty, greater competition among firms, and heightened concerns with the "bottom line." Others ascribe escalating incivility to the massive growth in numbers of practicing attorneys, reductions in social time that attorneys spend together outside of litigation, and decreases in the likelihood that attorneys will practice in front of the same court or across from the same opposing counsel. Finally, many point to the rapidly increasing speed with which communication takes place, which might leave insufficient time for reflection and attention to civility (DiLorenzo 1992; Podgor 1996; Smith 1997).

Amidst this flurry of discussion and debate, published empirical data documenting the nature and prevalence of incivility remain sparse. The U.S. Seventh Circuit is the only federal jurisdiction that has systematically investigated perceptions of incivility within its bench and bar. Of 82 judges and 1,297 attorneys who responded to an informal survey, more than $40 \%$ responded that incivility is a problem in the federal justice system (Committee on Civility of the Seventh Federal Judicial Circuit 1992a; 1992b). In addition, the ABA's Committee on Professionalism sponsored an important study in the mid-1980s, finding that $68 \%$ of corporate users of legal services saw declines in lawyer professionalism, as did $55 \%$ of state and federal judges (American Bar Association 1986). A host of smaller-scale studies-many sponsored by local bar associations and professional organizations-have also been conducted (e.g., the D.C. Bar's Task Force on Civility in the Profession, in McMurry 1996; Sells 1993), converging on the conclusion that incivility is rampant in contemporary legal practice.

Many have argued that incivility in the court system gives rise to wideranging, negative outcomes. Some point to the proliferation of jokes and stories in American popular culture characterizing attorneys as ruthless, heartless, aggressive, unbearable, and unethical (Pierce 1995). Others describe more direct, practical effects, including interference with the daily functioning of the courts as well as prohibitive increases in litigation expenses (Burger, 1971; Dondi Properties Corp. v. Commerce Savings and Loan Assoc., 121 F.R.D. 284 [N.D. Tex. 1988]; Tinkham 1990). Commentators contend that, on a broader level, incivility can hinder discussions and debates; prevent trials from serving their purposes; undermine public confidence in and respect for the judicial system; threaten the rights of individuals and society-in sum, posing a menace to democracy and the administration of justice (Aspen 1998; Burger 1971; Corr and Madden 1995; Honeywell 1994). Despite such grave speculations, no methodologically rigorous study has empirically determined how incivility affects the legal system and its constituents. 


\section{Gender Bias Task Forces}

While much of the legal profession has focused on civility and professionalism, others have investigated gender bias in the courts. In 1982, New Jersey became the first state to establish a task force to study gender bias in its courts. Six years later, the National Association of Chief Justices adopted a resolution calling on member states to conduct studies of gender, racial, and ethnic bias in the courts. By 1999, at least 40 states and five federal circuits had published reports examining gender bias, and a number of jurisdictions had also examined possible racial, ethnic, and religious bias in their court systems (for an extensive review of these studies, see Resnik 1996).

Specific task force findings differed, yet pointed to subtle (and sometimes not-so-subtle) patterns of offensive behavior regularly occurring in the legal system, most often directed at female participants. Moreover, female attorneys and judges were substantially more likely to observe such mistreatment than their male counterparts. Although much of this conduct occurred outside of the courthouse, offenses also often took place in the presence of judges, either in public or in chambers (Resnik 1996).

\section{Limitations of the Incivility and Gender Bias Studies}

Just as efforts to study incivility have largely failed to consider the unique issues of gender, gender bias reports have neglected questions of civility and professionalism. Thus, two major movements that both combat interpersonal mistreatment among legal professionals have unfolded for the most part independently. Not only has this resulted in inefficiency and redundancy, but both have also missed important elements of the problems under study, overlooking mistreatment falling at the intersection of professionalism and gender (Podgor 1996).

Most incivility and gender bias studies also share a number of shortcomings related to measurement. For example, many studies limited their inquiries to observations of incivility and bias. Such an assessment is problematic in that multiple respondents could report on the same incident(s), inaccurately inflating prevalence estimates. Respondents might also ignore incidents that are not salient to their own personal experiences, resulting in underestimates of the phenomenon under study. Other studies employed questions requiring respondents to assess offenders' intentions or motivations-subjective, psychological constructs that respondents cannot gauge reliably. Finally, studies such as the Seventh Circuit's (1992a; 1992b) inquired only about general perceptions of incivility, which-although informative--do not enable estimates of the prevalence of specific behaviors.

Beyond measurement flaws, many of these studies suffered from sampling problems. A number of gender bias task forces lacked the resources or 
foresight to follow up initial survey mailings with reminder postcards, phone calls, or second surveys. These single-mailing strategies yielded relatively low response rates (i.e., less than 35\%), introducing unknown biases into their samples. ${ }^{1}$ Many studies (including the Seventh Circuit's incivility study, 1992a; 1992b) did not employ random sampling techniques, instead surveying selected bar associations and professional organizations whose memberships did not reflect representative cross-sections of practicing attorneys in those regions. Such neglect of response rates and representative sampling raises serious questions about sampling error and the generalizability of results.

In addition to methodological limitations, past incivility and gender bias studies have neglected important topics related to interpersonal mistreatment in the courts. Most notably, they have ignored ways in which targets respond to or cope with interpersonal mistreatment. Psychological literature on stress and coping (e.g., Lazarus and Folkman 1984) posits that individual responses to stressful events can either exacerbate or attenuate the impact of these events. This suggests that individual experiences with, coping responses to, and consequences of incivility and harassment are related phenomena; ignoring any one of these yields an incomplete picture of this dynamic process. Thus, although the incivility and gender bias literatures have attempted to assess misbehavior in the courts and theorized on its outcomes, they have missed an important intervening variable-coping.

\section{The Current Study}

The present effort integrates and expands research in this area by examining interpersonal mistreatment directed at attorneys in federal litigation. We paid special attention to the relationship between general incivility and mistreatment that is explicitly gendered, and we investigated attorneys' responses to these situations. The current study also assessed the impact of such mistreatment on targeted individuals-providing an empirical addition to discourse on the topic. We pursued these goals with representative sampling, multivariate measurement and analysis, and systematic qualitative analysis.

\section{METHOD}

The findings described below resulted from an investigation of gender fairness in the U.S. Eighth Circuit. The intent of the larger study was to examine the role of gender as it affects attorneys, litigants, judges,

1. Some notable exceptions exist, such as the Second, Ninth, and D.C. Circuits' attorney surveys, which yielded responses rates ranging from $52 \%$ to $75 \%$. 
employees, and others who participate in the federal courts of this circuit (Eighth Circuit Gender Fairness Task Force 1997). This paper presents selected findings from the survey of attorneys. Preliminary data from this survey appeared in the Final Report and Recommendations of the Eighth Circuit Gender Fairness Task Force (1997). The current study follows up on those descriptive results with more advanced and detailed quantitative and qualitative analyses.

A detailed account of sampling, survey development, and survey administration procedures appears in the Eighth Circuit's Final Report (1997). To summarize, surveys were mailed to a disproportionate, stratified random sample of attorneys of record in the Eighth Circuit. Following a $53 \%$ return rate (which did not differ significantly by gender), statistical analyses focused on surveys from 1,425 women and 3,180 men.

\section{Quantitative Measures}

The survey was fairly lengthy, taking up to an hour for participants to complete; we will only review scales and questions that we analyzed in the present study. Note that we coded all quantitative items in the survey to reflect greater levels of the underlying construct, and-where appropriatewe summed them into their corresponding scales.

\section{General Incivility, Gender-related Incivility, and Unwanted Sexual Attention}

Items in the Interpersonal Mistreatment Scale (IMS) came from two primary sources. First, we developed six items, based on input from attorneys and judges, to measure experiences of general incivility and rudeness in federal litigation. Eleven additional items, adapted from Fitzgerald and colleagues' (1988) Sexual Experiences Questionnaire, assessed experiences of gendered incivility and unwanted sexual attention. The Sexual Experiences Questionnaire demonstrates excellent reliability and validity and is generally considered the most theoretically and psychometrically sophisticated instrument available for assessing incidence and prevalence of sexual harassment (Arvey and Cavanaugh 1995; Beere 1990).

For purposes of data reduction, we submitted the 17 -item IMS to principal components analysis with varimax rotation. The analysis yielded three groups of homogenous items ("subscales"), accounting for an overall $61 \%$ of the variance in these data. The 6-item General Incivility Scale (Cronbach's alpha $=.88$ ) captured experiences of rude, disrespectful, or condescending behavior. Sample items read "inappropriately interrupted you or cut you off" and "put you down or was condescending to you." The Gender-Related Incivility Scale $(5$ items; alpha $=.73$ ) measured rates of inappropriate or 
uncivil behaviors that were gendered in either their content (e.g., "made offensive remarks about women in your presence") or their targets (e.g., "publicly addressed you in unprofessional terms [e.g., 'honey,' 'dear']"). The 6 Unwanted Sexual Attention Scale (alpha $=.80$ ) items assessed experiences of sexually inappropriate behaviors ranging from sexually suggestive comments to unwanted touching to demands for sexual behavior in return for favorable treatment of a case (e.g., "attempted to establish a romantic or sexual relationship despite your efforts to discourage it").

All IMS items contained behavioral language, and none included the terms sexual harassment or gender bias, reducing demand characteristics and therefore increasing reliability. Instructions asked respondents to indicate whether they had experienced any of the behaviors in federal litigation during the previous five years from any judge, attorney, trustee, marshal, court security officer, or other court personnel. Participants responded to each item on a 5 -point scale, ranging from 0 (never) to 4 (many times).

\section{Coping with Interpersomal Mistreatment}

Participants endorsing any IMS items received questions about the "one situation" that had made the greatest impression on them. Among these questions was the Coping with Harassment Questionnaire (CHQ) (Fitzgerald 1990). The CHQ asked participants how they "handled" the one situation, providing a list of possible responses to interpersonal mistreatment. Fitzgerald (1990) conceptualized these coping responses as falling within two primary categories: internal coping strategies are cognitive methods of managing thoughts and emotions about a situation, whereas external coping strategies are more behavioral, problem-focused efforts to manage the situation itself. Table 1 presents all $\mathrm{CHQ}$ items falling within these two categories. Participants described the frequency with which they had employed each response in the "one situation," ranging from 0 (never) to 4 (many times). Note that, due to the heterogeneous nature of these CHQ items, we chose not to sum them into a scale.

\section{Outcomes of Interpersonal Mistreatment}

We relied on three measures of job outcomes, each having a Likert response-scale that ranged from 1 (strongly disagree) to 5 (strongly agree). A 4-item Job Satisfaction Scale (alpha $=.82$ ) assessed satisfaction with professional relationships and practice in the federal courts. For example, one item read "On the whole, I am satisfied with my professional work in federal court." We adapted 6 items from the Stress in General Scale (alpha $=.78$ ) (Smith et al. 1992) to measure the extent to which attorneys experienced work in federal court as stressful, pressured, or frustrating ("my experiences 


\section{TABLE 1}

Coping with Harrassment Behaviors and Percentage of Participants Using Each

\begin{tabular}{|c|c|c|c|c|c|}
\hline & \multicolumn{2}{|c|}{ Women } & \multicolumn{2}{|c|}{ Men } & \multirow[b]{2}{*}{$\chi^{2}$} \\
\hline & $\%$ & $n$ & $\%$ & $n$ & \\
\hline \multicolumn{6}{|l|}{ Internal } \\
\hline Tell yourself it wasn't important? & 66 & 484 & 55 & 516 & $19.16^{* * *}$ \\
\hline Just try to forget it? & 75 & 547 & 69 & 641 & $7.08^{* *}$ \\
\hline Just ignore it? & 80 & 587 & 73 & 681 & $10.55^{* * *}$ \\
\hline Blame yourself? & 22 & 158 & 21 & 199 & 0.02 \\
\hline Assume the person meant no harm? & 60 & 439 & 58 & 537 & 1.06 \\
\hline \multicolumn{6}{|l|}{ External } \\
\hline Try not to make the person angry? & 42 & 296 & 47 & 432 & $4.09 *$ \\
\hline Talk with someone for advice and support? & 50 & 366 & 34 & 317 & $43.04 * * *$ \\
\hline Try to avoid the person? & 35 & 258 & 28 & 267 & $8.48^{* *}$ \\
\hline Confront the person? & 32 & 240 & 24 & 226 & $14.51 * * *$ \\
\hline Report the situation informally? & 13 & 92 & 9 & 85 & $5.05 *$ \\
\hline Make a formal report? & 2 & 11 & 1 & 13 & 0.03 \\
\hline
\end{tabular}

$*_{p}<.05 .{ }^{* *} p<.01 .{ }^{* * *} p<.001$.

in federal court are more stressful than I'd like"). The Job Withdrawal Scale (alpha $=.72$ ) consisted of three items focusing on attorneys' thoughts and intentions of leaving federal legal practice altogether.

\section{Demographic Data}

Finally, participants responded to a series of questions concerning personal demographics, including gender, race/ethnicity, number of years of active law practice (including clerkships), and type of practice or position. For race/ethnicity, choices included African American/black, Asian American, Hispanic, Native American, European American/white, and Other. However, to obtain sufficiently large group sizes for meaningful analysis, we collapsed the former four groups into one "ethnic minority group," ${ }^{2}$ and compared it with the European-American/white group. Response options for years of active practice (i.e., tenure) fell along an ordinal scale, ranging from $0-5$ years to 31 or more years. Participants chose among 14 options to describe their type of practice, and we collapsed options into the following six categories: (1) solo or contract, (2) firm-partner, (3) firm-associate, (4) private corporation, (5) United States Attorney (AUSA/USA), and (6) government (not AUSA/USA) or public organization.

2. Combining African Americans, Asian Americans, Hispanics, and Native Americans into a single ethnic minority group is less than ideal, given the vastly different cultures, histories, and norms of these groups. However, the practicalities of data analysis forced this merger. 


\section{Qualitative Measures}

In the interest of allowing participants to describe their experiences in their own voices, open-ended questions followed quantitative items in several sections of the survey. Most relevant to the current paper, attorneys briefly described the "one situation" (of those they had experienced on the IMS) that had made the greatest impression upon them. In addition, after the $\mathrm{CHQ}$, attorneys provided narrative responses to the following questions: "If you reported the situation or made a complaint, what happened? If you didn't report the situation, what were your reasons?"' In total, 483 attorneys (265 women, 213 men, and 5 attorneys who chose not to identify their gender) responded to each of these open-ended questions. ${ }^{3}$

\section{RESULTS}

Analyses proceeded in four general stages. First, we examined the prevalence and nature of interpersonal mistreatment experienced by attorneys in federal practice. Next, we investigated factors associated with vulnerability to and perpetration of this conduct. The third set of analyses focused on attorneys' attempts at handling the inappropriate behavior. Finally, we concluded with a study of effects of interpersonal mistreatment on attorneys' professional well-being.

\section{Characteristics of Interpersonal Mistreatment}

Given the complete absence of prior methodologically rigorous studies of interpersonal mistreatment in federal practice, our first research question was purely exploratory: What patterns characterize attorneys' experience of interpersonal mistreatment in federal litigation? To address this question, we relied on both quantitative and qualitative data.

\section{Quantitative Data}

Analyses of the IMS revealed that, overall, $62 \%$ of participants (male and female) had experienced some form of interpersonal mistreatment

3. Fifteen responses to the first question (i.e., describing the one situation) and three responses to the reporting questions were too brief, vague, or unclear to be interpreted, and we thus dropped them from all subsequent analyses. We have no way of knowing for sure why more attorneys did not respond to qualitative questions about their uncivil experiences. Possible explanations include lack of energy or time to complete these questions, which were by far the most time-consuming; a belief that their uncivil experiences were too trivial to elaborate on; or an avoidance of discussing traumatic, uncivil experiences. All of these interpretations are clearly speculative. 
during litigation in the previous five years. Specifically, $27 \%$ described behaviors constituting general incivility only, and $5 \%$ reported gender-related incivility by itself. More than $22 \%$ had experienced both of these two types of mistreatment. A small but notable $3 \%$ encountered some form of unwanted sexual attention, which virtually always occurred in conjunction with the other two behaviors.

Closer examination revealed that respondents reported different patterns of these types and combinations of interpersonal mistreatment, depending on their gender $\left[\chi^{2}(6)=888.183, p<.001\right]$. Figure 1 illustrates this. For example, figure 1a shows that nearly $75 \%$ of women experienced

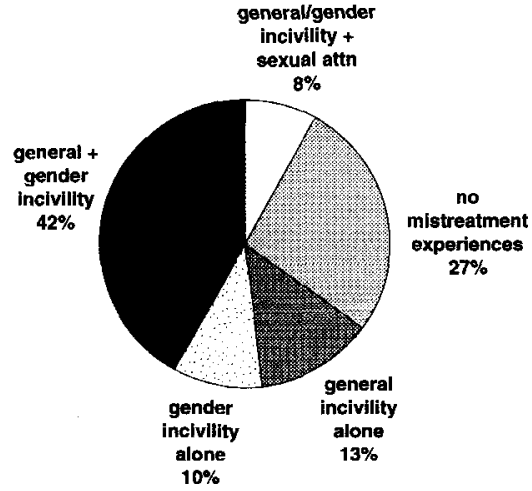

a. women

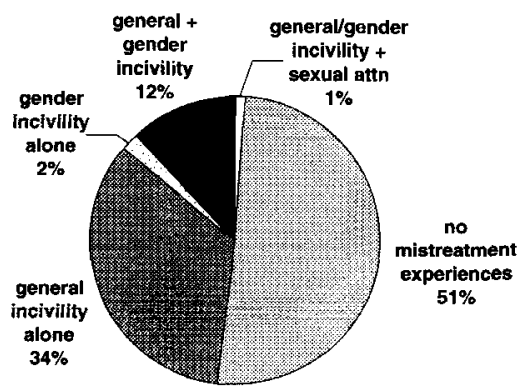

b. men

\section{FIGURE 1.}

Incidence rates of types and combinations of interpersonal mistreatment among all respondents.

some form of interpersonal mistreatment in the previous five years, compared to half of men (fig. 1b). Further, many more women than men reported being targets of gender-related incivility, either in isolation or in conjunction with general incivility. Similarly, more than $8 \%$ of women had encountered unwanted sexual attention in the context of federal litigation, compared to less than $1 \%$ of men; such experiences typically occurred in combination with other types of uncivil behavior. Overall, however, unwanted sexual attention was relatively rare in this environment.

Figure 2 further clarifies differences in men's and women's experiences. This figure displays data from targets only, excluding respondents who reported no experience with interpersonal mistreatment. The figure illustrates that when attorneys do encounter such behavior in litigation, much of what women experience is gender-related, whereas men's experiences consist largely of nongendered, nonsexualized, general incivility.

We also examined attorneys' total IMS scale scores, which combine information on frequencies, numbers, and types of behavior. Higher scores 


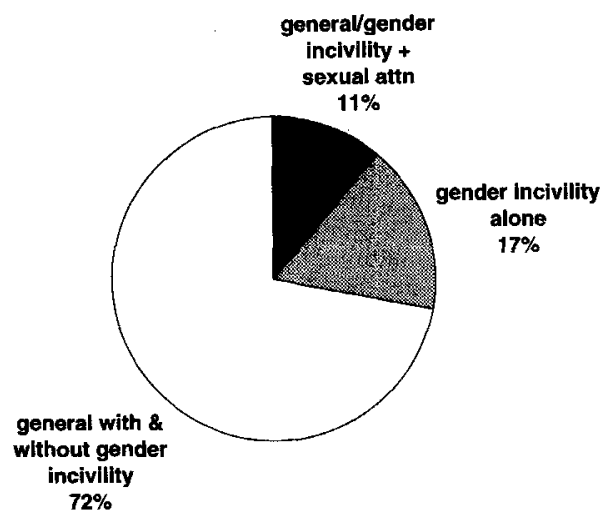

a. Women

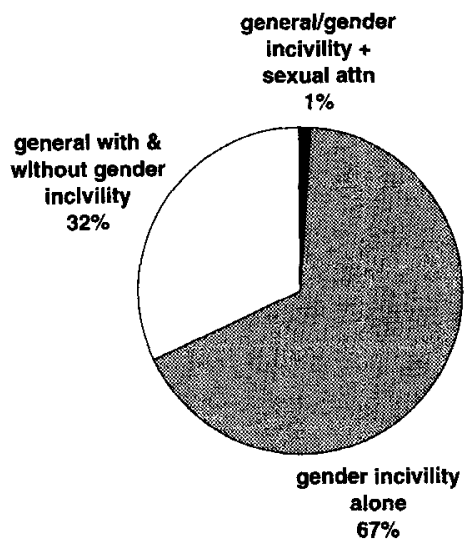

b. men

\section{FIGURE 2.}

Incidence rates of types and combinations of interpersonal mistreatment among targeted respondents only.

on this scale indicate either more frequent instances of the same type of mistreatment and/or more types of mistreatment-thus representing a global estimate of the severity of interpersonal mistreatment experienced by each attorney during the previous five years. Figure 3 displays percentages of IMS scores for female and male targets. Targets of both genders are most heavily represented in the lower range of the IMS scores, suggesting that

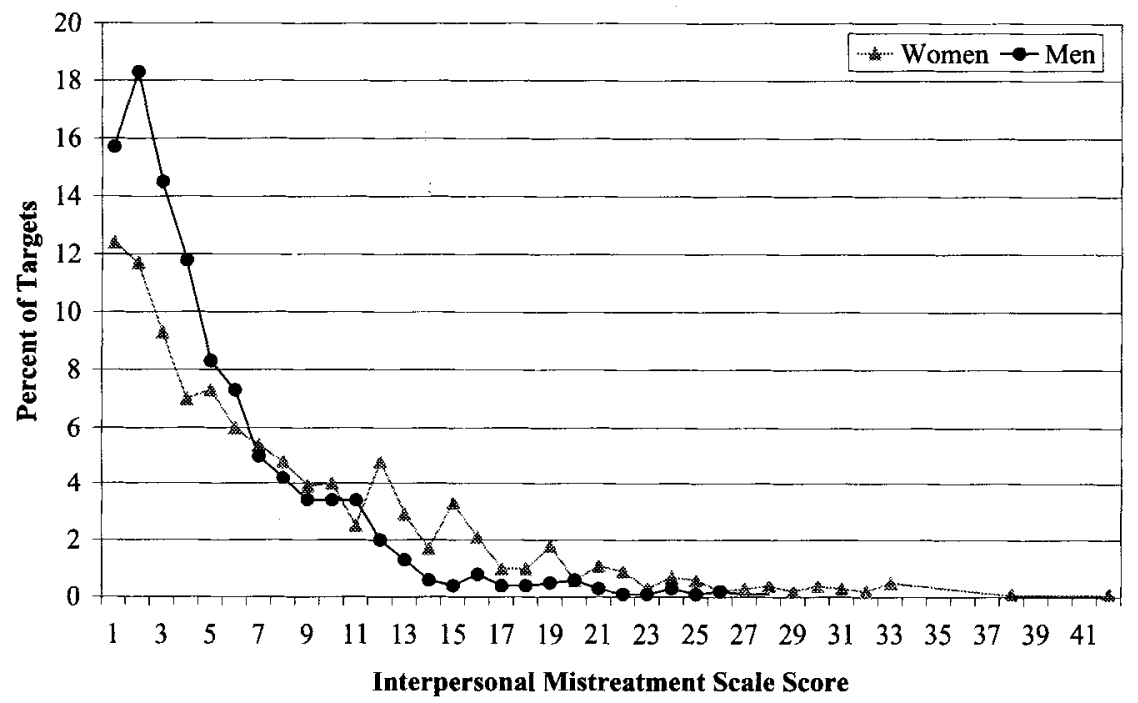

FIGURE 3.

Distributions of IMS scores for women and men. 
interpersonal mistreatment was somewhat infrequent in many of their experiences. Note that proportionately more men than women received these lowest IMS scores; this implies that, when male attorneys do experience interpersonal mistreatment in litigation, they are more likely than female targets to experience a low number or frequency of these behaviors. However, female and male experiences tend to converge in the moderate severity range. By contrast, gender differences re-emerge at the most severe levels of interpersonal mistreatment, which no men experienced; note on figure 3 how the women's IMS data extend well beyond those of the men.

\section{Qualitative Data}

Examination of the one situation narratives reveals additional details about experiences of interpersonal mistreatment. An iterative coding process $^{4}$ identified 11 thematic codes characterizing these behaviors. Sample quotes from each code appear in the appendix.

The first and by far largest coding category (applied to the narratives of $43 \%$ of women and $46 \%$ of men responding to this question) contained disrespectful or dishonest behaviors. This was the most heterogeneous category, including a variety of sources (lawyers, judges, clerks, etc.) and a range of severity, from mild discourtesy to extreme hostility to unethical strategic behavior. ${ }^{5}$ For example, these comments described condescension, discourtesy (e.g., refusal to shake hands), interruption, profanity, racism, sexism, "hard ball tactics," and unethical conduct (e.g., lying, breaching plea agreements). Numerous female respondents noted the gendered nature of certain behaviors (e.g., derogatory comments about attorneys' pregnancy), whereas others explicitly denied any link to gender.

The second largest category of behaviors ( $18 \%$ of women, $11 \%$ of men) reflected experiences of being ignored or excluded in the context of federal litigation. Closer examination revealed a gendered subtheme. Many women referred to interpersonal exclusion-for example, being ignored while attention focused on male colleagues. Some women also described "male

4. We conducted content analyses with an emergent design, deriving hypotheses and analytic strategies from the data itself (Glaser and Straus 1967; Huberman and Miles 1994a, 1994b). During initial coding, three of the authors read all narratives and identified themes and patterns-yielding a tentative set of thematic codes. A single narrative could receive multiple codes-or none at all-depending on its content.

In the second, focused, coding phase, two additional authors independently applied the codes to all of the narratives. They then met with the three initial coders to make final clarifications of the coding structure and resolve disagreements about coding assignments. Overall, the two focused coders agreed on $74 \%$ of the assignments. However, they applied certain codes more reliably than others, with a low of $51 \%$ for the professional discredit code and a high of $100 \%$ for the mistaken identity code.

5. Given the vast diversity of this category, we attempted to divide it into multiple subcategories. However, we could not identify smaller coding categories that could be applied reliably. 
bonding" situations, in which male judges or attorneys engaged in discussions and activities of mutual interest (e.g., golf, hunting) that excluded female colleagues. By contrast, a prominent theme among men was that their legal argument or position did not receive sufficient attention.

Other attorneys (14\% of women, $14 \%$ of men) described situations in which they were professionally discredited, typically involving implicit or explicit challenges to their competence, credibility, or integrity. Some attorneys $(11 \%, 11 \%)$ detailed experiences of silencing, in which others inappropriately interrupted or "talked over" them while speaking; such silencing came from a variety of sources and occurred both in and out of the courtroom. We coded certain responses $(11 \%, 6 \%)$ as gender disparagement, involving jokes and comments that were sexist, sex-role stereotypic, or trivializing of gendered legal issues (such as sex discrimination). Within this category, respondents of both sexes recounted experiences in which women's professional competence as a group was questioned or undermined. In addition, $9 \%$ of women and $5 \%$ of men gave accounts of threats or intimidation, usually professional (e.g., threats of sanctions, strategic "bullying" designed to gain legal advantage), but occasionally personal and/or physical.

A number of attorneys described being addressed unprofessionally $(8 \%$ of women, $0.5 \%$ of men), that is, with "pet names," endearments, or other inappropriate terms. Some attorneys $(6 \%, 1 \%)$ reported both general and sexually suggestive comments on their physical appearance or attire. Respondents were also mistaken for nonlawyers (e.g., court reporters, paralegals, runners; $7 \%, 15 \%$ ) and targeted with sexually suggestive comments or behavior $(4 \%, 2 \%)$ as well as physical or sexual touching $(4 \%, 0.5 \%)$. In this final category, most situations involved explicitly sexual touching; however, two included physically intimidating rather than sexually advancing contact. Interestingly, almost all respondents in these last five categories were women, and the few men's responses described mistreatment directed at female colleagues.

In summary, these one situation narratives corroborated quantitative results about frequencies and patterns of interpersonal mistreatment in federal litigation. The quantitative data suggested that general incivility is the most frequent form of mistreatment in this context; likewise, five of the most frequently applied narrative codes (i.e., disrespect/dishonesty, ignoring/exclusion, professional discredit, silencing, threats/intimidation) referred to generally uncivil conduct. The next most frequent behavior, according to both quantitative and qualitative results, involved gender-related incivility: gender disparagement, unprofessional forms of address, comments on appearance, and mistaken identity. Consistent with quantitative results, comments depicting unwanted sexual attention (coded as sexualized behavior and/or touching) were by far the most rare. 


\section{Demographics of Targets}

Using multiple regression analysis, we tested demographic variables to determine what predicted the frequency with which an attorney was targeted with interpersonal mistreatment in federal litigation over the previous five years. Due to the high co-occurrence of general, gendered, and sexualized incivility, we could not tease them apart to measure their predictors individually (in fact, such a separation would appear artificial and fail to capture the reality that these behaviors typically go hand-in-hand). Specifically, we summed scores on the three IMS subscales into one mistreatment score, which was then was regressed onto the following variables: tenure in the active practice of law, type of practice (represented by a five-level dummy variable, with the solo/contract attorneys arbitrarily designated as the undummied comparison group), minority status $(1=$ minority), and gender $(1=$ female $)$. To address the possibility that men and women might be targeted with different rates of interpersonal mistreatment depending on their legal practice experience or ethnicity, we also added gender-by-tenure and gender-by-ethnicity interactions. We hypothesized that variables indicating lower social power (i.e., being female or ethnic minority, having limited experience, working in lower-status jobs $)^{6}$ might increase vulnerability to interpersonal mistreatment.

Results revealed that this model accounted for a significant $10 \%$ of the variance in interpersonal mistreatment $(F(10,3917)=45.28, p<.0001)$. According to standardized beta coefficients, significant predictors were type of practice, minority status, and-in particular-gender. Specifically, USAs/AUSAs $(\beta=.10, p<.0001)$, ethnic minorities $(B=.05, p<.05),{ }^{7}$ and women $(B=.26, p<.0001)$ appeared more vulnerable to mistreatment compared to other attorneys.

\section{Instigators of Uncivil Behaviors}

Based on discourse in the sociolegal literature, we expected judges and attorneys to be frequent instigators of interpersonal mistreatment. Respondents who experienced any sort of uncivil or harassing behavior in Eighth Circuit litigation were asked to identify by category all individuals involved in such situations. These data appear in detail in the Eighth Circuit Final Report (1997). We briefly summarize these findings and bolster them with statistical significance tests.

6. For a classic review of bases of social power, see French and Raven 1959.

7. Note, however, that the beta coefficient for minority status is extremely small. The significance of this coefficient is likely a methodological artifact of our large sample size rather than a meaningful effect of minority status, so we did not attempt to interpret it. 
The great majority of attorneys identified the instigators of general incivility as judges or attorneys. In both types of situations, a significant association emerged between attorney gender and instigator position. Specifically, female targets were considerably more likely than male targets ( $75 \%$ vs. $44 \%)$ to report experiencing general incivility from other attorneys $\left[\chi^{2}(6)=312.576, p<.001\right]$, whereas male attomeys were somewhat more likely to identify judges as the source $\left[66 \%\right.$ vs. $56 \% ; \chi^{2}(6)=31.867$, p $<.001]$.

In the case of gender-related incivility, numerous respondents identified judges, attorneys, marshals, court security officers, and court personnel as instigators. Again, attorney gender related significantly to instigator position, in that proportionately more female than male targets identified other attorneys $\left[66 \%\right.$ vs. $\left.53 \% ; \chi^{2}(5)=74.396, p<.001\right]$ and court personnel $\left[53 \%\right.$ vs. $\left.35 \% ; \chi^{2}(5)=45.827, p<.001\right]$ as instigators.

Attorneys represented the primary source of unwanted sexual attention, with $80 \%$ of female and $62 \%$ of male targets describing fellow attorneys as instigators. However, because too few participants reported unwanted sexual attention, we could not conduct meaningful statistical tests of association between target gender and instigator position.

\section{Coping with Uncivil Behaviors}

The current study attempted the first analysis to date of attorney responses to interpersonal mistreatment. We hypothesized that results would mirror those found in the psychological literature on organizational victimization (for a review, see Fitzgerald, Swan, and Fischer, 1995), with targets of interpersonal mistreatment rarely confronting instigators or reporting the mistreatment to anyone in authority. Instead, we expected most targets to endure or ignore the behavior without taking action, deny its seriousness, avoid the instigator, or discuss the situation with peers.

\section{Quantitative Data}

Respondents who experienced any sort of uncivil or harassing behavior in the Eighth Circuit noted whether any of 11 strategies described their response to the one situation; table 1 presents endorsement rates of each strategy by gender. Most targeted attorneys (55\%-80\%) responded to interpersonal mistreatment by attempting to ignore, minimize, forget about, or deny harm in the situation. By contrast, only one-quarter to one-third of targets altered their behavioral reactions to the perpetrator by either confronting or avoiding that person. Further, only one in ten attorneys-on average-chose to report the misconduct informally, and almost no one pursued formal grievances. 
Further analysis revealed gender disparities in coping behavior. By far the largest difference surrounded women's greater use of social support compared to men. Reflecting the next-largest gender differences, many more women than men denied the importance of the situation and/or confronted the instigator. Slightly more women also tried to forget the situation, report it informally, or avoid the instigator. Conversely, men were somewhat more likely than women to cope with the situation by avoiding actions that might anger the instigator.

\section{Qualitative Data}

To gain in-depth understanding of attorneys' responses to the one situation-particularly with respect to reporting-we analyzed the content of narrative responses to the following questions: "If you reported the situation or made a complaint, what happened? If you didn't report the situation, what were your reasons?" The analysis procedure was identical to that employed for the one situation narratives. A total of seven codes characterized responses to the situation, and an additional seven codes captured reasons for not reporting. The appendix presents sample quotes from each category. ${ }^{8}$

Attomey reactions to the one situation. Most respondents did not describe how they reacted to the one situation. Of the few who did, the majority detailed very proactive, assertive responses. Some ( $7 \%$ of women, $12 \%$ of men who responded to this question) reported the situation to a supervisor or other superior. Such notification was typically - but not always-informal. However, a few respondents reported the matter in the context of an appeal to the Circuit Court. Other attorneys $(10 \%, 5 \%)$ stated that they "handled the situation" personally, with some describing the specific actions taken (e.g., confrontation, apology demand) and others offering little or no elaboration. In addition, a small number of attorneys $(3 \%, 0.5 \%)$ discussed the situation with peers, who often advised the respondent to forget or "drop" the issue because it "wasn't that big a deal."

Beyond describing their responses to the one situation, a handful of respondents specified the ultimate outcome of either their response or the situation itself. Of these, most $(5 \%, 5 \%)$ stated that no consequences resulted, because either (1) the respondent did not report the situation to anyone in authority, or (2) a complaint was made (to a judge, partner, trustee, U.S. attorney) without redress. In contrast, certain attorneys $(5 \%, 3 \%)$ described situations that resulted in some form of intervention, involving a range of sources and variety of forms (e.g., admonishments, apologies, changes in behavior, formal investigation). Finally, a few respondents ( $1 \%$,

8. Overall, the two raters involved in focused coding agreed upon $72 \%$ of the coding assignments. The procedural unfamiliarity code received the highest rate of agreement (94\%), whereas the won code received the lowest $(25 \%)$. 
$2 \%)$ stated that the situation was preserved as part of the formal record, in the transcript from a trial, deposition, or rule 16 conference.

Reasons for not reporting. By far the most common rationale for not reporting the one situation was that the respondent thought it inappropriate to do so, for various reasons (25\% of women, $23 \%$ of men who responded to this question). Many suggested that it is inherently inappropriate to report interpersonal mistreatment in legal practice, because such problems should be handled individually. Others described their experience as too trivial to warrant complaint, sometimes noting that the conduct did not violate the law or other rules. Interestingly, some attorneys explained their decision not to report by stating that the behavior resulted from the offender's personality or temperament, was commonplace, or represented a natural extension of the adversarial legal system.

Whereas these former reasons for not reporting seemed to minimize the significance of the one situation, others focused on the risk or futility of reporting. For example, respondents expressed concerns about retaliation (directed at not only themselves but also their clients) from the bench, court personnel, or colleagues $(19 \%, 13 \%)$. Some $(11 \%, 1 \%)$ described a related worry that reporting could backfire by harming their professional image. Many women in this category expressed gender-related concerns, such as fears of being labeled "weak" or "feminazi." A number of attorneys (17\%, $14 \%$ ) responded that reporting would be futile, resulting in no positive change.

Some respondents focused on reporting mechanisms rather than outcomes. Six percent of women and $1 \%$ of men explicitly stated that no legitimate avenue of recourse exists. Others $(5 \%, 3 \%)$ admitted being unfamiliar with reporting procedures, often not knowing how or with whom to file a report. Some respondents in this category seemed to raise the issue rhetorically or even sarcastically (e.g., "report to whom???"), implying the absence of such procedures.

Finally, a handful of attorneys stated that reporting would have been unnecessary, because either a judge had witnessed the situation $(2 \%, 2 \%)$ or the attorney had won the legal point, issue, or case $(1 \%, 4 \%)$.

\section{Effects of Uncivil Behaviors}

To assess direct and indirect effects of interpersonal mistreatment on attorneys' professional well-being, we tested a series of structural equation models with latent variables, using LISREL 8 (Jöreskog and Sörbom 1996). ${ }^{9}$

9. One of the benefits of this analysis is that it allows us to adjust for imperfections in the measurement of our variables, via a "measurement model." Correlation matrices and measurement model details are available from the first author; the current paper presents only 
We hypothesized that such mistreatment would lower job satisfaction and increase job stress, which in turn would lead to greater job withdrawal; figure 4 presents the structure of this proposed model. Note that we measured

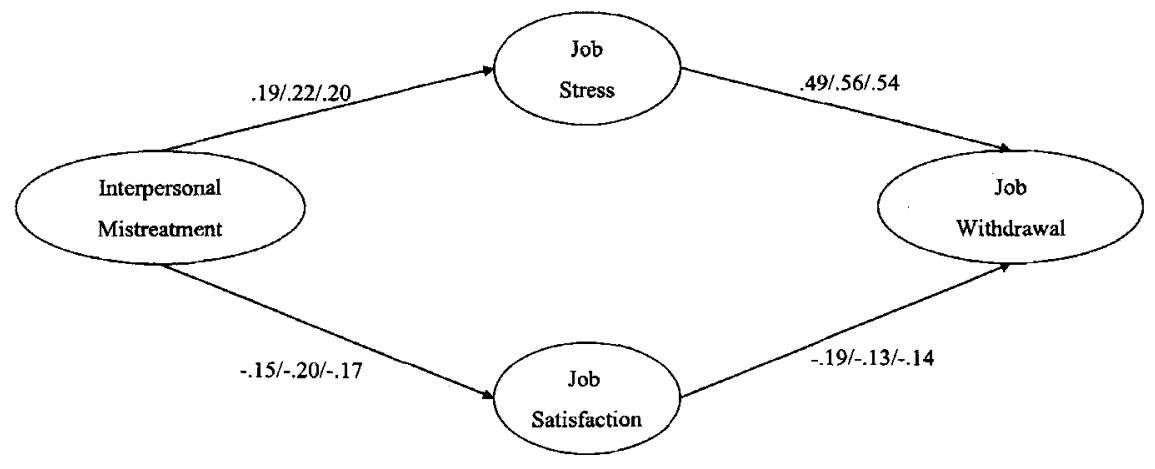

FIGURE 4.

Structural model with standardized path coefficients for within-group analysis of women/within-group analysis of men/and simultaneous analysis of both genders. All path coefficients are significant, $p<.01$.

the frequency of interpersonal mistreatment with a variable that summed across experiences of General Incivility, Gender-Related Incivility, and Unwanted Sexual Attention.

First, we tested our model separately for women $(n=1118)$ and men ( $n=2,416$ ), confirming that it fit both groups' data quite well (for both, RMSEA $<.05, \mathrm{GFI}=.98, \mathrm{AGFI}=.97, \mathrm{NNFI}=.98$ ). We then tested a twogroup model, analyzing women's and men's data simultaneously to determine whether relations in the model differ by gender. The final simultaneous model closely approximated the data (RMSEA $=.06 ; \mathrm{GFI}=.98$, and NNFI $=.97$ ), failing to uncover gender differences. That is, regardless of gender, more frequent experiences of interpersonal mistreatment were associated with lowered job satisfaction and increased job stress. Further, the less satisfied and more stressed that attorneys felt, the more they considered leaving federal law practice.

\section{DISCUSSION}

Good manners, disciplined behavior and civility-by whatever name-are the lubricants that prevent lawsuits from turning into combat. More than that it is really the very glue that keeps an organized society from flying apart. (Chief Justice Warren Burger 1971, 215)

"structural model" results. We assessed the fit of each model using a number of indices: Root Mean Square Error of Approximation (RMSEA), Goodness of Fit Index (GFI), Non-Normed Fit Index (NNFI), and-where appropriate-Adjusted Goodness of Fit Index (AGFI). 
Recent years have seen the legal profession become increasingly concerned with incivility and gender bias eroding the professionalism, authority, and justice of the federal courts. Nevertheless, this misbehavior that the field so decries has remained something of a mystery--many have experienced it, some have perpetrated it, others have lectured on it-but few can scientifically describe its prevalence, nature, and impact within the larger court system. Speculations abound, but they lack empirical support. The current study addresses this gap by systematically examining the interpersonal mistreatment experienced by 4,605 attorneys in federal litigation.

\section{How Extensive Is the Problem?}

Our results portray a federal litigation environment where rudeness, disrespect, gender disparagement, and sexually inappropriate behaviors are alarmingly common. Specifically, almost two-thirds of attorneys have experienced general incivility, gendered incivility, and/or unwanted sexual attention while in litigation in the Eighth Circuit federal courts-with women encountering such mistreatment more frequently than men. Nearly all of these experiences involve general incivility and-for most male targetsgeneral incivility alone. According to our narrative results, generally uncivil behavior takes many forms-from mildly annoying to harmfully abusive to blatantly unethical. For women targets, by contrast, these generalized forms of mistreatment typically go hand-in-hand with incivility explicitly tied to their gender. Overall, women are overwhelmingly more likely than men to encounter gender-related incivility. Ethnic minority status, type of legal practice, and years of legal experience cannot explain gender differences in vulnerability to interpersonal mistreatment.

Narrative comments further explicate gendered patterns in experiences of mistreatment. Women's unique perspectives on general incivility suggest that this behavior is often not "general" at all for them, but rather is gendered incivility of a less blatant type. That is, some female attorneys take pains to explain that they attribute their uncivil experiences to gendereven if the mistreatment was not explicitly gendered on its face. Other women go to equal lengths to deny any impact of gender on their experiences. Nevertheless, in both of these cases, women apparently engage in a process that few men do when experiencing incivility during federal litigation-attempting to determine the relevance of gender to their experience. This uncertain process undoubtedly exacerbates the anxiety inherent in the situation and constitutes a cognitive burden that women bear as members of a targeted group - always wondering what effect, if any, their status has on negative interpersonal experiences. Further, our results statistically validate many women's subjective experiences: "women in the United States have 
long understood that their gender has affected, and sometimes defined, their interaction with legal institutions" (Resnik 1996, 952).

These results suggest that patterns of interaction in federal litigation replicate problematic gender relations from the larger society, including stereotypic, sexualized, and abusive treatment of women. Some of the interpersonal mistreatment that our participants describe fits the characteristics of "sex-role spillover" (Gutek 1985; Gutek and Morasch 1982), when expectations for women's behavior at home permeate the work realm. That is, some misbehavior involves treating women attorneys as mothers, wives, sexual partners, and daughters-roles in which some men are more accustomed to or comfortable seeing women. Women's narratives underscore this, describing experiences of such familiar or infantalizing terms of address as sweetheart, dear, and Miss Girl Lawyer. Sexualized jokes further suggest that conceptualizations of women as sex objects follow them into professional contexts, where such fantasies clearly do not belong.

It is alarming to note that nearly $8 \%$ of women attorneys (but virtually no men) have experienced unwanted touches, sexual advances, sexually suggestive comments, and sexual coercion. This is perhaps a most egregious form of sex-role spillover, as these highly inappropriate and intrusive behaviors should never take place in a courtroom, judge's chambers, deposition, or other litigation context. This prevalence estimate may appear low, especially in comparison to other literature on sexual harassment and studies of gender bias in the courts. However, because our survey addressed such a narrow context - assessing only behavior experienced in federal litigationit provides a very conservative estimate of the extent of sexually inappropriate behavior directed at attorneys. Unlike most other gender bias studies, the current survey did not inquire about other workplace settings (e.g., law firms, public defenders' offices) where attorneys spend the bulk of their time and likely experience the most unwanted sexual attention.

In contrast to women, male attorneys' experiences of interpersonal mistreatment primarily consist of general rudeness or discourtesy-such as professional exclusion, interruptions, condescension, or professionally demeaning comments. Narratives further suggest these uncivil experiences rarely prime men to consider the relevance of their gender to the situations. In fact, one common complaint among male attorneys was that their legal arguments were not given sufficient consideration, raising the question of whether such experiences constitute "incivility" at all.

Our methodological approach to the study of interpersonal mistreatment may partly explain gender differences in experiences. That is, we drew on the cognitive stress literature (Lazarus and Folkman 1984) and conceptualized incivility and harassment as workplace stressors. This literature defines psychological stress as "a relationship between the person and the environment that is appraised by the person as taxing or exceeding his or her 
resources and endangering his or her wellbeing" (Lazarus and Folkman 1984, 21, emphasis added). This conceptualization necessarily implies a subjective component to experiences and definitions of incivility and requires an individual focus. Thus, we attended to targets' experiences, interpretations, appraisals, and so forth-rather than instigators' intentions or observers' impressions-in our attempts to understand incivility in the federal court system. This approach mirrors Felstiner, Abel, and Sarat's conceptualization of perceived injury, which places individuals "at the center of the sociological study of law" and defines injurious experiences as "any experience that is disvalued by the person to whom it occurs" (1980-81, 633-34). Our individual focus could, in part, explain some of the gender differences that we see in targets of mistreatment, because individuals vary in what they experience as stressful, offensive, harassing, and so forth.

\section{Who Is Behaving Badly?}

Prevention of interpersonal mistreatment in the courts cannot begin without an accurate understanding of its sources. Commentators largely focus on behaviors originating from "attorneys behaving badly," as if attorneys are by and large the only instigators. The current study, however, demonstrates the inaccuracy of such a conclusion. Attorneys certainly constitute a large source of all types of this misconduct in litigation -indeed, they are the most frequent instigators of all interpersonal mistreatment targeted at women attorneys. However, men encounter more general incivility from judges than from fellow attorneys, and more than half of women cite judges as instigators of such generalized mistreatment. In our measurement of general incivility, we focused heavily on behaviors that would originate from legal professionals rather than court staff (for example, interruption of attorney "statements" is a behavior that has little relevance to interactions with court employees or security), partly explaining why most instigators of these behaviors are judges and attorneys.

Judges also direct gender-related incivility at almost one-quarter of women and men targets, and more than one in ten women received unwanted sexual attention from members of the bench. These findings are particularly alarming, given judges' power to set the social standards of their courtrooms. With such models to follow, the prevalence of interpersonal mistreatment among attorneys (and court personnel; see Cortina et al. 2001) becomes less surprising.

An interesting instigator pattern differentiates the experiences of male versus female targets, suggesting that societal gender hierarchies interact with local work structures in affecting interpersonal mistreatment within federal litigation. That is, women attorneys are most likely to experience this misbehavior from their male counterparts, reinforcing men's heightened 
status in gendered social arrangements. In contrast, male attorneys are less likely to experience mistreatment from female colleagues (who are "below them" in the gender stratification of the larger society) but more likely to encounter this behavior from judges (situated "above them" in the institutional hierarchy). These patterns of mistreatment thus reinforce social and occupational structures that place women below men, and attorneys below judges.

Social dominance theory suggests that, not only can interpersonal mistreatment reinforce power structures, but also structures can motivate abusive behavior. Briefly, this theory claims that all societies maintain a hierarchy of power, with at least one social group having dominance over other groups. This power can take many forms, including different expectations and norms, better access to valued resources, and greater prestige (e.g., Carli 1999; French and Raven 1959). Further, the dominant group or groups maintain their power in part by using various forms of oppression against less fortunate groups (e.g., Sidanius 1993). Social power theory thus helps explain greater exploitation of attorneys occupying lower positions in the social structure.

More specifically, with respect to interpersonal mistreatment of women in the legal workplace, gender dominance theory holds that this type of victimization functions as a mechanism of social control and a response to female autonomy (Brownmiller 1975; Koss et al. 1994; MacKinnon 1979). That is, women's social and occupational advances threaten the status quo of male dominance and female subordination, inspiring hostility toward women as a means of maintaining control. ${ }^{10}$ This seemingly trivial incivility can thus perpetuate the relegation of women to the margins of professional society.

\section{So What?}

Some critics of movements to combat incivility and gender bias acknowledge that the mistreatment occurs, but ask "so what?"- suggesting that the ramifications of these behaviors are trivial or nonexistent. The current study dispels such myths, documenting that general, gendered, and sexualized incivility in the federal courts adversely affects practicing attorneys-both female and male. Specifically, the more often that attorneys encounter interpersonal mistreatment in federal litigation, the less satisfied they become with their work and the more job stress they experience. Less job satisfaction and greater job stress, in turn, translate into stronger

10. For a discussion of societal gender relations and their impact on workplace discrimination and harassment, see Tangri, Burt, and Johnson 1982 or Gutek and Morasch 1982. For a specific discussion of this issue in the legal system, see Padavic and Orcutt 1997 or Schultz 1998. 
desires to leave the practice of law. Gender similarities are more notable than differences in this process. That is-although women and men tend to experience different levels and types of interpersonal mistreatment in federal litigation-when they do experience the behavior, they suffer parallel consequences.

Organizational psychology tells us that thoughts of and intentions to quit are highly predictive of decisions to actually quit (e.g., Hackett 1989; Sullivan and Bhagat 1992; Wright and Bonnett 1993). Thus, our outcome data suggest that an indirect effect of incivility and gender bias in litigation is the profession's loss of valuable attorneys-especially women, who experience higher rates of mistreatment. These quantitative results resounded in some of the narrative comments as well, as exemplified by the following:

Public humiliation in front of a client in a bankruptcy proceedings. This is common before this one judge. You can't take it personally. I know people that don't practice bankruptcy anymore because of this judge. (Female respondent; emphasis added)

This association between mistreatment in and exit from the legal workplace mirrors results of past economical and sociological research, which focused specifically on gendered (Kay 1997) and sexualized (Laband and Lentz 1998) forms of interpersonal hostility.

These findings illustrate how interpersonal mistreatment experienced in the very narrow context of litigation can influence attorneys' more global job satisfaction and stress-effects of which might extend to the larger court system. That is, organizations with more satisfied members tend to be more effective (Ostroff 1992). Offering a possible explanation for this fact, satisfied employees often engage in more pro-organizational behaviors (e.g., staying late to assist a colleague; Bateman and Organ 1983). With such proorganizational efforts implemented by numerous individuals, the organization can generally adapt better to personal and interpersonal needs that would otherwise interfere with productivity. In additional, and perhaps most important, research has linked increased job stress with decreased work performance (again, see Sullivan and Bhagat 1992).

In sum, the negative consequences of experiencing interpersonal mistreatment in the federal courts have implications far beyond the mistreated individual. The proliferation of these behaviors could diminish attorneys' abilities to represent their clients effectively and impair the functioning of the larger organization or court system. These data thus suggest avenues by which interpersonal misconduct can potentially interfere with the administration of justice. 
Our narrative data also demonstrate that mistreatment of attorneys does not escape the attention of others who pass through the court system:

The judge was extremely disrespectful and would make unnecessary and rude comments. Also, would roll her eyes during testimony. The clients noted and commented on the disrespect. (Female respondent; emphasis added)

A judge was offensive and disrespectful toward both me and my client in the presence and hearing of a jury. (Male respondent; emphasis added)

Such narratives demonstrate that attorneys' experiences of hostile and offensive behavior are not simply personal problems between quarrelling individuals, because adverse consequences can extend to bystanders. With much of this behavior on public display, interpersonal mistreatment among legal professionals could diminish respect for and confidence in the legal system, undermining the normative authority of the courts.

\section{What's an Individual to Do?}

Our quantitative data uncover gender differences in responses to interpersonal mistreatment, with women relying more than men on most coping strategies. Women's more extensive coping may simply reflect their more severe experiences of misbehavior compared to men. Supporting this possibility, past research on harassment coping suggests that use of virtually all coping strategies increases linearly with harassment frequency/severity; as targets encounter more harassment, they logically implement more cognitive and behavioral efforts to manage the stress of the situation (Fitzgerald et al. 1995; Gruber and Bjorn, 1982, 1986).

Reflecting by far the largest gender difference in coping, women mobilized considerably more social support than did men, which is consistent with psychological literature on support- and help-seeking behavior. That is, previous studies have found women-compared to men-to recruit more support from social networks in times of stress (Ashton and Fuehrer 1993; Butler, Giordano, and Neren 1985; Hobfoll et al. 1994). Gender-role socialization represents a possible explanation for such differences, as society traditionally reinforces women more than men for collective, prosocial, interdependent behavior. The present study speaks to the vitality of these traditional gender asymmetries within the modern legal world.

Our quantitative results also reveal appeasement (i.e., response strategies that avoid angering the instigator) to be the only coping behavior that men used more heavily than women. Instigator patterns may partly explain this result, as more men than women encountered interpersonal mistreatment from judges. These male targets may restrict their coping efforts to 
cognitions and behaviors that mollify judicial instigators, fearing retaliation from these most powerful members of the federal court organization.

\section{Why Don't They Just File a Complaint?}

Despite the confrontational nature of the American adversarial model of justice, our quantitative results suggest that most attorneys avoid direct confrontation when responding to interpersonal mistreatment. Consistent with research on coping with sexual harassment (for a review, see Fitzgerald et al. 1995), attorneys most commonly ignore, deny, or minimize the situation. Few use informal means for reporting their experiences to individuals in authority, and virtually none make any kind of formal complaint with the Eighth Circuit (results very much in keeping with the 1991 study on sexual harassment by the Women's Legal Defense Fund). Clearly, regardless of whether or not a reporting mechanism exists in the Eighth Circuit, attorneys largely do not use it to accomplish redress of their uncivil experiences.

The few attorneys who narrated their reasons for not reporting interpersonal mistreatment painted a hostile and hazardous picture of the litigation context. They frequently avoided reporting because they appraised the mistreatment as an expected and unavoidable part the legal profession-as if the legal system breeds the inappropriate behavior. Some attorneys indicated that the primary deterrent to reporting was fear-of harming their clients' cases, damaging their professional image, losing favor with the judge, and so forth. These results imply a failure on the part of the courts to provide attorneys with safe and effective mechanisms for reporting mistreatment. In fact, many attorneys seemed to question our competence as researchers for even inquiring about reporting a federal judge with lifetime tenure.

Attorneys' reasons for not reporting interpersonal mistreatment are consistent with the empirical and theoretical literature on whistle-blowing in organizations, which underscores the danger inherent in blowing the whistle on powerful wrongdoers (see Miceli and Near 1992). Drawing on Black's (1976) sociological theory of justice, Miceli and colleagues explain this upward deviance (action taken by a lower-status person against higherstatus person) as "deviant behavior and a more serious offense in a socially stratified society . . . it is most likely to evoke the greatest sanction" (Miceli et al. 1999,147$)$. They add that exposing the misbehavior of a highly placed member of the organizational hierarchy-thus characterizing that person as unlawful, unethical, or inappropriate-questions that hierarchy. The organization's dominant coalition, including the wrongdoer, could therefore retaliate against the target to correct this challenge to organizational authority (Near, Dworkin, and Miceli 1993). Indeed, an empirical study of Eighth Circuit court employees documented that employees endured more social 
and work-related retaliation when they spoke out against powerful organizational members (Cortina and Magley 2001). Thus, attorneys' hesitation to report the misbehavior of superiors may reflect well-founded apprehension and prudent caution.

\section{Where Do We Go from Here?}

This paper documents an alarming pattern of general and gendered incivility among professionals in federal litigation. Clearly, current efforts are inadequate for resolving this systemic problem. These findings speak to the need for more extensive and novel approaches to prevention, professional rehabilitation, education, and proactive intervention-particularly from individuals in authority (e.g., the judiciary; see Lonsway et al. 2002). These efforts must take a comprehensive approach to be effective, addressing the many forms and sources of this misbehavior and, on a larger level, the organizational and social structures that support it.

Ellen Pogdor (1996) offers a promising approach to prevention and intervention. Specifically, movements and educational programs combating gender bias might do well to dovetail with those addressing more general incivility, because the "dual avenues taken . . . fail to provide a concerted force toward the elimination of bias in the legal profession" (Podgor 1996, 328). This strategy would more adequately reflect the multidimensional nature of interpersonal mistreatment, which comes in general, gendered, and sexualized varieties. Such programs would also attract broader audiences, being relevant to both women and men and avoiding resistance met by interventions that exclusively target gender bias, sexual harassment, and so forth. We thus join Podgor $(1996,328)$ in her belief that "coalescing the goals of the professionalism and gender bias commissions will provide both efficiency and expanded energy" for the two efforts.

\section{Limitations}

Like any scientific research, our findings are not without limitations. Psychologists typically regard a 53\% response rate from a professional sample completing a lengthy mail survey as quite good; nevertheless, our final sample could be biased in unknown ways. Although we were able to check against the possibility of gender-biased response rates, lack of information on additional characteristics of our population prohibited more in-depth response-rate analyses. One might wonder whether personal experiences of interpersonal mistreatment might influence attorneys' decisions to participate in this research. However, we embedded our IMS items in a long survey, which also inquired about numerous other topics not covered in the 
present paper (e.g., professional demographics, committee appointments). We therefore believe that few respondents would have immediately perceived this as an "incivility survey" or "sexual harassment survey." Nev. ertheless, additional systematic response biases are unknown.

Because we were unable to weight our quantitative findings back to population proportions, our prevalence data represent "rough" estimates at best. Further, only $17 \%$ of attorneys targeted with mistreatment elaborated on their experiences in narrative format. Thus, until corroborated with future research, we must be cautious in making generalizations from these data across the Eighth Circuit and other jurisdictions.

Gender differences in self-reports of mistreatment could be attributed, at least in part, to perceptual differences between women and men. The theoretical and empirical literature clearly indicates that individuals with less institutional power endure more stereotyping and discrimination, so they become more sensitized to even subtle behaviors. ${ }^{11}$ Thus, women's descriptions of more extensive interpersonal mistreatment could reflect an actual gender difference in incidence rates, heightened detection of more subtle mistreatment, increased sensitivity due to a lower status in traditional gender hierarchies, or all of the above.

Although we were able to identify certain factors (e.g., gender, practice as USA/AUSA) that increase attorneys' vulnerability to interpersonal mistreatment, regression models accounted for small proportions of variance in vulnerability. This is not particularly surprising, given the complex, multiply determined nature of psychological constructs such as incivility. Other factors that could also affect vulnerability include the organization's formal and informal policies, local social norms, and workplace demographics. However, an assessment of all potential triggers of misconduct was beyond the scope of the present survey-if indeed this is even possible.

\section{CONCLUSION}

In conclusion, the current study echoes and underscores the call for greater civility, in all its many guises, in the federal court system. We document various manifestations and sources of interpersonal mistreatment, making apparent the need for multifaceted interventions targeting a range of audiences. Our study also highlights individual coping strategies that attorneys employ when encountering such behavior, illustrating that reporting mechanisms represent an insufficient avenue of redress. Instead, preventive and proactive efforts at the court, district, and circuit levels are necessary. Finally, we present the first systematic evidence to date of the toll that this mistreatment takes, suggesting effects that extend well beyond the

11. For a review of psychological literature on stereotyping and power, see Fiske 1993. 


\section{LAW \& SOCIAL INQUIRY}

individual target. Ironically, despite the centrality of justice to the federal courts, they are no more immune than other organizations to the harms of everyday interpersonal injustices. 


\section{APPENDIX \\ SAMPLE QUOTES FROM ALL THEMATIC CODES}

\section{Disrespect/Dishonesty}

"The lawyer was generally condescending and insisted on addressing me by the wrong name despite my correcting him" (female).

"On more than one occasion I have seen district judges be condescending, rude and interrupting in informal matters, frequently to the embarrassment of counsel and usually without provocation" (male).

"Opposing attorney was uncooperative to the point of being obnoxious" (female).

"Assistant U.S. attorney breached plea agreement and lied" (male).

\section{Ignoring/Exclusion}

"During various conferences in chambers, senior judge and opposing counsel (well-known older male attorney) carried on with each other and exchanged war stories at length as though I wasn't in the room. It put me at a great disadvantage with the judge" (female).

"They just ignored my sound legal arguments" (male).

\section{Professional Discrediting}

"An attorney for the U.S. Trustee's office implied I was lying in open court. The judge 'accepted my professional representation' but did not reprimand the attorney" (female).

"Before a jury, district judge made remarks and rulings that were professionally demeaning, indicating I didn't know the law and the legal argument I was advancing was preposterous" (male).

\section{Silencing}

"Some AUSA's in our district will interrupt a defense attorney's questions or argument before it is completed if they disagree with the argument or questions" (male).

"During deposition, opposing counsel rudely cut off questioning and kept talking and yelling louder over my objections. . . . Told me to back off, honey!" (female).

\section{Gender Disparagement}

"During a deposition opposing counsel informed me that I had no case and if I weren't a woman I would be smart enough to recognize that fact" (female).

"Trustee made comment about you can't be that smart if you've got a $d \_k$ between your legs" (male). 
"Federal trial judge asked me at bench conference. . . What do you thinkthey should have fired him just because he slapped some gal on the butt? These incidents aren't important'" (female).

\section{Threats/Intimidation}

"An opposing attorney made implicitly threatening comments to me several times. . . . I believed he was mentally unstable. I had some fear that he might try to cause harm to me, my teenagers or my home" (female).

"An attorney threatened to report me to the state supreme court if I continued to prosecute a case. He was trying to pressure me to settle the case" (male).

\section{Unprofessional Address}

'Opposing counsel refused to address or refer to me by name or as 'counsel.' He only called me 'honey, 'dear,' and 'missy.' The judge finally threatened to sanction him because he wouldn't stop after repeated verbal reprimands from the court" (female).

"In a bench trial, the judge referred to me as 'dear' and by my surname, preceded by 'Mrs.' He referred to the other lawyer (male) by his first name. Bad impression for client" (female).

\section{Appearance Comment}

"When a case was called, a male attorney and I approached the podium at which point he opened his remarks with a compliment on my physical appearance rather than the matter at bar" (female).

"Two male attorneys bantered across table about appearance of court reporters they'd hired, while case we were preparing was a sexual harassment issue" (female).

\section{Mistaken Identity}

"Attorney sees me (the AUSA) and much younger agent, who is male, and assumes I am agent and he is attorney. This happens often. On occasion, I am seen as court reporter or clerk" (female).

"Marshal questioning why I was in the courtroom because he assumed that I was not an attorney" (female).

\section{Sexualized Behavior}

"'Hitting' on me, flirting, asked out to lunch/dinner" (female).

"Attorney and client made sexually explicit jokes about me and my client during unmediated settlement conference and in the hall during breaks during trial" (male). 


\section{Touching}

"An attorney ... kissed my neck, put his arms around me, and touched my thighs while we were working on a case together" (female).

"The judge was touching female colleagues in a way that might have been considered offensive" (male).

\section{Reporting}

"I reported it to two partners who did nothing" (female).

"We included the bias issue in our appeal brief, rather than reporting it as a formal complaint" (male).

\section{Personal Response}

"I demanded an apology and got it" (female).

"I handled the situation at the time--told him to please stop interrupting mekept asserting myself until I finished what I was saying" (male).

"Threatened to amend the complaint to add this conduct as evidence of continuing pattern of harassment-case settled" (female).

\section{Peer Discussion}

"I reported the situation to one of my colleagues and to my significant other" (female).

"Discussed with others her perceived shortcoming and found others who had similar experiences" (male).

\section{Formal Record}

"It was on the record during a rule 16 conference and the magistrate took care of it at the time" (female).

"It was already public, to complain further would hurt my client's interests" (male).

\section{No Consequence}

"My complaint to the U.S. trustee and the assistant U.S. trustee was discounted" (female).

"Partner in charge did not want to pursue" (male). 


\section{Intervention}

"Judge dealt with it in open court appropriately" (male).

"Firm investigated. Offered an apology and generous severance package" (female).

"U.S. attorney spoke with judge" (male).

\section{Inappropriate}

"This is a subtle and interpersonal dynamic that is not appropriately 'reported' or even complained about" (female).

"Part of the business. You have to learn to deal with arrogant, discourteous lawyers, or get out of the practice" (male).

\section{Retaliation Concerns}

"I didn't report it because this is a federal judge with life tenure and making an issue would merely prejudice me/my clients in the future" (male).

"Court personnel can make an attomey's work life miserable, and it is not worth the trouble to report an incident and suffer the consequence of 'lost files' or other future problems" (female).

\section{Futile}

"I didn't believe a motion would do more than cost money to my client" (female).

"After reading every reported case in the Federal Courts of the 8th Circuit on recusal and judicial discipline, I thought it was a lost cause" (male).

"Assume judges can get away with practically anything they want" (female).

\section{Image Concerns}

"I wouldn't want people to think I was whining, complaining, or could not handle the situation" (female).

"I'd be labeled a troublemaker" (female).

\section{Procedural Unfamiliarity}

"Whom do I report to? No clear line of responsibility for this person" (female).

"To whom do you report that a judge is in a bad mood?" (female). 


\section{No Recourse}

"This did not appear to be a case in which there was any recourse available" (female).

"I investigated reporting the incident but was informed that there was no recourse" (female).

\section{Judicial Witness}

"Judge dealt with it in open court appropriately" (male).

"Other judges observed the behavior but did nothing in the courtroom" (female).

\section{Won}

"I won the motion and didn't want any further hassles" (female).

"I was successful in my objection, the judge reprimanded them, and in the end they were the ones that looked like fools" (male).

\section{REFERENCES}

American Bar Association. 1986. In the Spirit of Public Service: A Blueprint for the Rekindling of Lawyer Professionalism. 112 F.R.D. 243.

Arvey, Richard D., and M. A. Cavanaugh. 1995. Using Surveys to Assess the Prevalence of Sexual Harassment: Some Methodological Problems. Journal of Social Issues 51:39-52.

Ashton, William A., and Ann Fuehrer. 1993. Effects of Gender and Gender Role Identification of Participant and Type of Social Support Resource on Support Seeking. Sex Roles 28:461-76.

Aspen, Marvin E. 1998. It's How You Play the Game. Trial, July, 28-32.

Bateman, Thomas S., and Dennis W. Organ. 1983. Job Satisfaction and the Good Soldier: The Relationship between Affect and Employee "Citizenship." Academy of Management Journal 26:587-95.

Beere, Carole A. 1990. Gender Roles: A Handbook of Tests and Measures. New York: Greenwood Press.

Black, Donald. 1976. The Behavior of Law. New York: Academic Press,

Brownmiller, Susan. 1975. Against Our will: Men, Women and Rape. New York: Simon and Schuster.

Burger, Warren. 1971. The Necessity for Civility. 52 F.R.D. 211.

Butler, Timothy, Stephen Giordano, and Steven Neren. 1985. Sex Roles 13:515-24.

Carli, Linda L. 1999. Gender, Interpersonal Power, and Social Influence. Joumal of Social Issue 55 (1): 81-99.

Committee on Civility of the Seventh Federal Judicial Circuit. 1992a. Interim Report of the Committee on Civility of the Seventh Federal Judicial Circuit. 143 F.R.D. 371.

- 1992b. Final Report of the Committee on Civility of the Seventh Federal Judicial Circuit. 143 F.R.D. 441. 
Corr, Kelly P., and Patrick M. Madden, 1995. Goodbye, Rambo-Hello, Mr. Rogers? For the Defense 37 (12): 8-14.

Cortina, Lilia M., and Vicki J. Magley. 2001. Retaliation in the Context of Interpersonal Mistreatment: The Dangers of Speaking Out. Paper presented at the Annual Meeting of the American Psychological Society, June 14-17, Toronto, Ontario, Canada.

Cortina, Lilia M., Vicki J. Magley, Jill Hunter Williams, and Regina Day Langhout. 2001. Incivility in the Workplace: Incidence and Impact. Journal of Occupational Health Psychology. 6 (1): 64-80.

DiLorenzo, Louis P. 1992. Civility and Professionalism. New York State Bar Journal 68 (1): 8 .

Eighth Circuit Gender Fairness Task Force. 1997. Final Report and Recommendations of the Eighth Circuit Gender Fairness Task Force. Creighton Law Review. 31 (1): $1-181$.

Felstiner, William L. F, Richard L. Abel, and Austin Sarat. 1980-81. The Emergence and Transformation of Disputes: Naming, Blaming, Claiming. Law and Society Review 15:631-54.

Fiske, Susan T. 1993. Controlling Other People: The Impact of Power on Stereotyping. American Psychologist 48:621-28.

Fitzgerald, Louise F. 1990. Assessing Strategies for Coping with Sexual Harassment: A Theoretical/Empirical Approach. Paper presented at the Annual Meeting of the Association for Women in Psychology, March, Tempe, Arizona.

Fitzgerald, Louise F., Sandra Shullman, Nancy Bailey, Margaret Richards, J. Swecker, Yael Gold, Alayne J. Ormerod, and Lauren Weitzman. 1988. The Incidence and Dimensions of Sexual Harassment in Academia and the Workplace. Journal of Vocational Behavior 32:152-75.

Fitzgerald, Louise F., Suzanne Swan, and Karla Fischer. 1995. Why Didn't She Just Report Him? The Psychological and Legal Implications of Women's Strategies for Responding to Sexual Harassment. Journal of Social Issues 51:117-38.

French, John R. P., and Bertram Raven. 1959. The Bases of Social Power. In Studies in Social Power, ed. D. Cartwright, 150-67. Ann Arbor: University of Michigan Press.

Glaser, Barney F., and Anselm L. Strauss. 1967. The Discovery of Grounded Theory: Strategies for Qualitative Research. Chicago: Aldine.

Gruber, James E., and Lars Bjorn. 1982. Blue-Collar Blues: The Sexual Harassment of Women Autoworkers. Work and Occupations 9 (3): 271-98.

- 1986. Women's Responses to Sexual Harassment: An Analysis of Sociocultural, Organizational, and Personal Resource Models. Social Science Quarterly 67:814-26.

Guccione, Jean. 1997. Bar Leaders Take Aim at Incivility of "Rambo" Lawyers. Los Angeles Daily Journal, April 14, 1.

Gutek, Barbara A. 1985. Sex and the Workplace: Impact of Sexual Behavior and Harassment on Women, Men, and Organizations. San Francisco: Jossey-Bass.

Gutek, Barbara A., and Bruce Morasch. 1982. Sex-Ratios, Sex-Role Spillover, and Sexual Harassment of Women at Work. Journal of Social Issues 38:55-74.

Hackett, Rick D. 1989. Work Attitudes and Employee Absenteeism: A Synthesis of the Literature. Journal of Occupational Psychology 62:235-48.

Hansen, Mark. 1991. Incivility a Problem, Survey Says. ABA Journal 77:22.

Hobfoll, Stevan E., Carla L. Dunahoo, Yossef Ben-Porath, and Jeannine Monnier. 1994. Gender and Coping: The Dual-Axis Model of Coping. American Journal of Community Psychology, 22:49-82.

Honeywell, Mark G. 1994. How to Be on the Offensive without Being Offensive. Trial $30(6): 86$ 
Huberman, A. Michael, and Matthew Miles. 1994a. Data Management and Analysis Methods. In Handbook of Qualitative Research, 428-44. Thousand Oaks, Calif.: Sage Publications.

1994b. Qualitative Data Analysis: An Expanded Sourcebook. Thousand Oaks, Calif.: Sage Publications.

Jöreskog, Karl and Dag Sörbom. 1996. LISREL VIII: User's Reference Guide. Chicago: Scientific Software International.

Kay, Fiona M. 1997. Flight from Law: A Competing Risks Model of Departures from Law Firms. Law and Society Review 31:301-55.

Koss, Mary P., Lisa A. Goodman, Angela Browne, Louise F. Fitzgerald, Gwendolyn Puryear Keita, and Nancy Felipe Russo. 1994. No Safe Haven: Male Violence against Women at Home, at Work, and in the Community. Washington, D.C.: American Psychological Association.

Laband, David N., and Bernard F. Lentz. 1998. The Effects of Sexual Harassment on Job Satisfaction, Earnings, and Turnover among Female Lawyers. Industrial and Labor Relations Review 51:594-607.

Lazarus, Richard S., and Susan Folkman. 1984. Stress, Appraisal and Coping. New York: Springer.

Lonsway, Kimberly A., Leslie V. Freeman, Lilia M. Cortina, Vicki J. Magley, and Louise F. Fitzgerald. 2002. Understanding the Judicial Role in Addressing Gender Bias: A View from the Eighth Circuit Federal Court System. Law 8 Social Inquiry 27(2):205-233.

MacKinnon, Catherine. 1979. Sexual Harassment of Working Women. New Haven, Conn: Yale University Press.

McMurry, Kelly. 1996. Lawyer Incivility: War Games or Bad Manners? Trial 32:10-12.

Miceli, Marcia P., and Janet P. Near. 1992. Blowing the Whistle: The Organizational and Legal Implications for Companies and Employees. New York: Lexington Books.

Miceli, Marcia P., Michael Rehg, Janet P. Near, and Katherine C. Ryan. 1999. Can Laws Protect Whistle-Blowers? Results of a Naturally Occurring Field Experiment. Work and Occupations 26:129-51.

Near, Janet P., Terry M. Dworkin, and Marcia P. Miceli. 1993. Explaining the WhistleBlowing Process: Suggestions from Power Theory and Justice Theory. Organization Science 4:393-11.

Ninth Circuit Gender Bias Task Force. 1994. The Effects of Gender in the Federal Courts: The Final Report of the Ninth Circuit Gender Bias Task Force. Southern California Law Review 67:745-1106.

Ostroff, Cheri. 1992. The Relationship Between Satisfaction, Attitudes, and Performance: An Organizational Level Analysis. Journal of Applied Psychology 77:963-74.

Padavic, Irene, and James D. Orcutt. 1997. Perceptions of Sexual Harassment in the Florida Legal System: A Comparison of Dominance and Spillover Explanations. Gender and Society 11:682-98.

Pierce, Jennfier L. 1995. Gender Trials: Emotional Lives in Contemporary Law Firms. Berkeley and Los Angeles: University of California Press.

Podgor, Ellen. 1996. Lawyer Professionalism in a Gendered Society. South Carolina Law Review 47 (2): 323-48.

Resnik, Judith. 1996. Asking about Gender in the Courts. Signs: Journal of Women in Culture and Society 21:952-90.

Ring, Leonard M. 1992. The Incivility Crisis. Trial 29 (8): 78.

Schultz, Vicki. 1998. Reconceptualizing Sexual Harassment. Yale Law Joumal 107:1683-1805. 
Sells, Benjamin. 1993. Looking in All the Wrong Places for Civility. Los Angeles Daily Joumal, 106:7

Sidanius, James. 1993. The Psychology of Group Conflict and the Dynamics of Oppression: A Social Dominance Perspective. In Explorations in Political Psychology, ed. Shanto Iyengar and William J.McGuire, 183-219. Durham, N.C.: Duke University Press.

Smith, John Stuart. 1997. Civility in the Courtroom from a Litigator's Perspective. New York State Bar Journal, May/June, 28-30.

Smith, Patricia C., William K. Balzer, Gail H. Ironson, Karen B. Paul, Bob Hayes, Sarah Moore-Hirschl, and Luis Fernando Parra. 1992. Development and Validation of the Stress in General (SIG) Scale. Paper presented at the Seventh Annual Convention of the Society for Industrial and Organizational Psychology, May, Montreal, Canada.

Sullivan, Sherry E., and Rabi S. Bhagat. 1992. Organizational Stress, Job Satisfaction and Job Performance: Where Do We Go from Here? Journal of Management 18:353-74.

Tangri, Sandra S., Martha R. Burt, and Leanor B. Johnson. 1982. Sexual Harassment at Work: Three Explanatory Models. Journal of Social Issues 38:33-54.

Tinkham, Thomas W. 1990. Incivility Revisited. Bench and Bar of Minnesota 47 (7): 5. Wallis-Honchar, Cornelia. 1997. Right to Remain Silent Can Quiet Incivility. Chicago Daily Law Bulletin 143 (87): 5.

Women's Legal Defense Fund. 1991. Sexual Harassment in the Workplace. Washington, D.C.: Women's Legal Defense Fund.

Wright, Thomas. A., and Douglas G. Bonnett. 1993. Role of Employee Coping and Performance in Voluntary Employee Withdrawal: A Research Refinement and Elaboration. Journal of Management 19:147-61. 